\title{
DE LA RETÓRICA A LA ANTROPOLOGÍA
}

\author{
Andrea Battistini \\ (Universidad de Bolonia)
}

RESUMEN: Relato autobiográfico, pleno de vitalidad y de erudición, que despliega viquistamente la historia de "B.", a la vez que nos va mostrando las etapas de un proceso de investigación y estudio viquiano centrado en el ámbito de la estética y en el de la filosofía retórica. Un proceso que no lo es menos de autoconocimiento centrado en la historia y en el acto de filosofar vinculado a la actividad retórica del ingenio, de la fantasía, de la imaginación.

Palabras clave: Vico, 350 Aniversario, estética, retórica, ingenio, fantasía, humanismo, Scienza nuova, A. Battistini.

\section{From rhetorics to anthropology}

ABSTRACT: This is an autobiographical story, full of vitality and erudition, that displays in Vico's style the history of "B.", while showing us the stages of a process of Vichian research and study focused on the fields of aesthetics and rhetorical philosophy. A process of self-knowledge focused on history and the act of philosophizing, as it is linked to the rhetorical activity of ingenuity, of fantasy and of imagination.

KeYwords: G. Vico, 350 th Anniversary, aesthetics, rhetoric, ingenuity, fantasy, humanism, New science, A. Battistini.

\section{Dalla retorica all'antropologia}

RIASSUNTO: Si tratta di una storia autobiografica, piena di vitalità ed erudizione che mostra vichianamente la storia di "B", mentre ci illustra le fasi di un processo di ricerca e di studio vichiano focalizzato sull'ambito dell'estetica e su quello della filosofia retorica. Un processo nientemeno che di autoconoscenza incentrata sulla storia e sull'atto del filosofare, legata all'attività retorica dell'ingegno, della fantasia e dell'immaginazione.

PARole ChiAVE: Vico, $350^{\circ}$ Anniversario, estetica, retorica, ingegno, fantasia, umanesimo, Scienza nuova, A. Battistini.

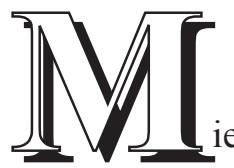

ientras investigaba la historia de la autobiografía, en la que también estaba incluida la de Vico, tropecé a menudo con una serie de advertencias en contra de la auto-escritura. En la Ética a Nicómaco (IV 1125a), Aristóteles advier-

Este artículo responde a una invitación expresa por parte de la Dirección de la Revista para este volumen especial por el $350^{\circ}$ Aniversario del nacimiento de G. Vico, habiendo superado los criterios de valoración y del proceso de aceptación. 
te de que el magnánimo «ni habla de sí mismo ni de los demás»; para Cicerón «nihil necesse est mihi de me ipso dicere» (Cato maior, IX); para Pascal «le moi est haïssable» (Pensées ed. Brunschwicg No. 455). El mismo Vico, después de escribir su autobiografía, «se concedió a sí mismo todo el poder» para que «bajo ningún pacto en el mundo» fuese publicada. Su texto, sin embargo, se publicó en solitario, mientras que en mi caso me encuentro en muy buena compañía, por lo que considero que, como a él, me cabe «el más alto honor de ser el último de todos en esta colección tan prestigiosa» y agradezco tanto a José Manuel Sevilla como a Miguel A. Pastor el haberme invitado a participar en ella. Pero, extremando la modestia, haré como Vico y hablaré de mí en tercera persona, designándome como B.

B. conoció a Vico en la escuela secundaria, cuando el profesor de historia de la filosofía leyó una antología de la Scienza nuova editada por Franco Amerio, un historiador de formación católica que, por este motivo, polemizó con la interpretación de Croce. Si es cierto que «la naturaleza de las cosas no es más que el nacimiento de ellas», el primer encuentro con Vico estuvo, por lo tanto, muy lejos de tener una lectura neoidealista. En la Universidad, B. se graduó en literatura italiana con una tesis sobre las técnicas retóricas de la prosa de Vico. En aquella época, en los años Sesenta del siglo pasado, apenas existían estudios sobre el lenguaje y el estilo de Vico, y en realidad puede decirse casi lo mismo de estos últimos cincuenta años. Para escribir en esta área los ensayos de Mario Fubini fueron todo un referente, pero, según B., estaban contaminados por un teleologismo a priori, en el sentido en el que Fubini, como revisionista crociano, veía un progreso imparable desde la primera a la última edición de la Scienza nuova. Y no solo eso, sino que además consideraba que las habilidades retóricas de Vico, y su docencia universitaria en esa disciplina, no solo eran irrelevantes sino incluso perjudiciales para la formación de su estilo, en línea con las tesis aún románticas de Croce, para quien la retórica no era más que una «pseudociencia empírico normativa». Por el contrario, para B. la retórica tuvo una importancia mayor e iba más allá de ofrecer los medios necesarios para realizar un discurso eficaz y persuasivo. Inspirándose en las investigaciones de Ernesto Grassi, que valoraba la retórica de Vico para poder conectar mejor su pensamiento con la tradición del Humanismo, B., sin buscar esas ascendencias, le asignó un verdadero papel gnoseológico, porque consideró que los primeros hombres de la humanidad, aun sin darse cuenta, llevaron a cabo sus primeros conocimientos a partir de metáforas (como aquella del cielo entendido como un "vasto cuerpo animado»), de metonimias tomando el efecto (el trueno y el rayo) por la causa (la voz de Júpiter), o de sinécdoques tomando al individuo (Hércules) por la especie (todos los que trabajaron para cultivar las tierras). En suma, en ausencia de un poder abstracto y universalizador, la retórica con sus figuras expresivas suministró a aquellos primitivos seres las analogías que necesitaban para pasar de lo particular a lo general. 
Si los mecanismos de la retórica les dieron a las bestias la función gnoseológica necesaria para convertirse en hombres, a los intérpretes modernos les han permitido llevar a cabo la tarea hermenéutica de interpretar el pensamiento y la mentalidad primitivos. A estos últimos Vico les pide ayuda para conseguir que nuestra mente rejuvenezca, regresando al punto de partida de aquellas creaciones fantásticas de la infancia de la humanidad. Para poder leer la gramática del mito y la poesía, dada su naturaleza polisémica y connotativa, no hay otro método más que la retórica, ya que tiene por costumbre dar una interpretación que nunca es literal sino más bien (en el sentido etimológico de la palabra) alegórica, puesto que los tropos y las figuras son formas que siempre «están en lugar» de otra cosa. La interpretación de Vico guarda relación con la búsqueda de los principios «dentro de las modificaciones de nuestra propia mente humana». Es, por tanto, una metamorfosis creativa («modificazioni»), del mismo tipo que la que el retórico hace con el lenguaje neutral y referencial. Por su parte, el antropólogo hace que la retórica siga el mismo camino de retroceso, porque busca, detrás del lenguaje claro y distinto, el grosor opaco de los tropos originales que conservan el sentido de capítulos enteros de la historia social, política y económica de la humanidad.

En Vico, que dedica el segundo libro de la Scienza nuova a la institución de la enciclopedia del saber en la etapa histórica de la edad de los héroes, la retórica también tiene un papel taxonómico, en cuanto que no tiene contenidos específicos sino que es una técnica que se puede aplicar a cualquier disciplina y a cualquier tipo de discurso. En este sentido, sus competencias son omnicomprensivas y su función, al no guardar relación con ninguna especialidad exclusiva, sirve para mantener unido el saber, mucho más extenso que el campo de aplicación de la lógica que cree que solo a ella le incumben las cuestiones relativas a la verdad. La retórica, en cambio, trata de lo verosímil y probable, del pensar y del sentir. En De nostri temporis studiorum ratione, Vico sostiene que la retórica trata de todas las cosas «quae omnia sapiunt», es decir, literalmente, de «cosas que saben, que huelen a todo». Con ello quiere decir que al conocimiento le concierne, además de la razón, también los sentidos y, por tanto, todo lo relativo al hombre, en sus componentes tanto racionales como sensibles, fantásticos y perceptivos. Esta es la razón por la que, como profesor de retórica que fue, Vico debía «para desempeñar su cargo de manera adecuada, ser culto en todas las artes y las ciencias». Debido a esto la Scienza nuova pudo crear el sistema inclusivo de la «sabiduría poética», ya que la poesía que hacían instintivamente los primeros hombres, en épocas «ilustradas y cultas» se organiza reflexivamente desde la perspectiva multidisciplinar de la retórica, que trata precisamente del peculiar código connotativo de la poesía.

Por su formación como italianista, finalmente B. atribuyó a la retórica una cuarta competencia gnoseológica junto a las competencias hermenéuticas, taxonómicas y expositivas. Vico contaba con un serio problema de «transcripción», rela- 
cionado con la dificultad que suponía relatar la forma de vivir y pensar de la era de los dioses y de los héroes con el lenguaje de la era de los hombres. Hay que tener en cuenta que esta «transcripción» está hecha con técnicas retóricas puesto que, aun utilizando la razón para interpretar la mentalidad primitiva, en su prosa las ideas asumen las características de una imagen sensible que permite llegar a visualizar el razonamiento. Los conceptos abstractos en su obra se concretizan en diversos objetos, en diversas empresas heráldicas, a partir de hipótesis y mitos que utilizan sustantivos relativos al cuerpo humano. T.S. Eliot explicaría este método expositivo como un «sensous thought», pero ya antes Vico en su carta a Gherardo degli Angioli había definido este estilo como un «pensar». Con este procedimiento retórico Vico habla de los «simplones de Grocio», de las «cigarras de Hobbes», de las «ranas de Epicuro», de la «hez de Rómulo», de la misma manera en que habla de los «surcos de Cadmo», de las «piedras de Deucalión y Pirra» o de las «cadenas de oro poético» del Hércules galo. En todos estos casos, el equivalente plástico encarna todo el proceso de pensamiento que se transmite mediante un procedimiento visual. El proceso de personificación, tan necesario para la perspectiva mítica y para la creación de las primeras figuras de la retórica, persiste en su exposición moderna de la Scienza nuova y tiene como consecuencia la dramatización del texto filosófico, circunstancia esta que ha sido poco considerada por los críticos.

A tales tesis B. había dedicado en 1975 La degnità della retórica y exactamente veinte años después La sapienza retorica di G. Vico. Mientras tanto había encontrado la confirmación de la relevancia de estos estudios en una edición de lujo de las Institutiones Oratoriae de Vico (1989), el único de sus textos que Nicolini había excluido por considerarlo totalmente insignificante y que solo se conocía a través de unos breves resúmenes que Laterza había añadido a la edición original de sus obras completas. Junto a este hito, que dio relevancia al aspecto retórico de las transcripciones ecdóticas, se desarrolló también en Italia, debido quizás al éxito del estructuralismo, que llegó a definirse como una «Rhétorique Renaissance», con la valorización de las obras de Perelman, Barthes, Genette y de las traducciones de Mooney (Vico e la tradizione della retorica, 1992) y de Vickers (Storia della retorica, 1994), de las cuales B. hizo la introducción para Italia. De tal forma que B. se encontró cerca de los intereses de los viquianos estadounidenses. No fue, pues, por casualidad que Verene lo invitara a Atlanta para dictar un curso sobre «Vico and Rhetoric». Sin embargo, los objetivos finales eran diversos. Tenían en común la importancia central que le daban a la retórica, pero Verene, al igual que Tagliacozzo, lo hizo porque la consideraba lo contrario de la lógica y porque estaba vinculada a la actividad del ingenio, de la fantasía, de la imaginación. Estos aspectos, indudablemente presentes en Vico, tuvieron gran importancia en los Estados Unidos porque, considerados en clave actual y militante, se asumieron como antídotos que podían ser propuestos a una civilización estadounidense enferma a causa de la espe- 
cialización y de un racionalismo exasperado. Y no solo esto, sino que, al considerar los puntos básicos en los que se fundan las ciencias humanas, la retórica se contraponía al imperialismo del saber tecnológico y se presentaba como un medio para realizar síntesis en las que, al añadir elementos distantes entre sí, se podía superar el divorcio entre las llamadas dos culturas. B. por otro lado, aunque no niega que Vico también puede enseñarle algo al hombre actual y que, si este lo escucha, puede ayudarle a corregir ciertos errores, le asigna a la retórica un rol antropológico, considerándola históricamente como el instrumento privilegiado con el que se puede reconstruir la mentalidad primitiva. B. fue en esa dirección y, tal vez cuando ya fue demasiado tarde para ello, se dio cuenta de que un gran gran intelectual como LéviStrauss, que durante mucho tiempo anduvo distraído con el éxito de Rousseau, en sus últimos años se había interesado por la modernidad del Vico antropólogo, por no mencionar a Edward Said, que reivindicó la profundidad de su humanismo, donde el conocimiento «poético» no solo es la causa de un aprendizaje receptivo, sino que también lo crea desempeñando así el papel activo «de discernir tanto los detalles como el conjunto de los elementos que conforman el lenguaje, la historia humana y la sociedad».

Si estos maîtres à penser procedieron con la genialidad de sus intuiciones, B., mucho más modestamente, se dedicó a una obra de excavación filológica e historiográfica que no ha tenido mucha visibilidad. Dejando a los historiadores de la filosofía el examen de la relación de Vico con los «cuatro autores» recordados por él, comenzó a buscar otras fuentes citadas en la Scienza nuova que, con la excepción de Paolo Rossi, habían sido mucho menos estudiadas. La inteligencia de Vico trasciende con creces la pesada erudición de los siglos XVI y XVII, pero es allí donde tuvieron lugar un sinnúmero de «pruebas filológicas» en apoyo a sus originales tesis antropológicas y lingüísticas. Ya en 1974 B. llamó la atención sobre el Etymologicon linguae latinae de Gerhard Johannes Voss para comprobar cuánto le debía Vico y qué diferencias hermenéuticas tenían, siguiendo así el camino señalado por Pietro Piovani y recorrido por Paolo Rossi, que había leído los volúmenes de Bochart, Fludd, Horn, Kircher, Marsham, Schook, Spencer. En los cincuenta años que tuvo la oportunidad de escribir sobre Vico, B. examinó de vez en cuando su background humanístico sobre los estudios de las pasiones a través de las obras de Vives, investigó la copiosa literatura connotativa y de los lenguajes icónicos que podían haber influido en la formación del «vocabulario mental» contenido en la Scienza nuova, trazó los fundamentos históricos con los que los tropos quedaron reducidos a cuatro tal como se indica en la sección de la «Lógica poética» y encontró en los manuales de retórica del siglo XVII las premisas que, a través de la antonomasia, dieron lugar al concepto del universal fantástico. Entre los modelos que sirvieron para arrojar luz sobre la «antigüedad heroica», comparó al «feroz y salvaje» Homero con el «doctísimo» Virgilio, a pesar de pertenecer a una etapa posterior. 
Finalmente, en relación con lo que se conoce como obras menores de Vico, B. relacionó la oración por la muerte de Angiola Cimmino con el rol pedagógico que el tema funerario desempeñaba en la oratoria barroca y conectó el De rebus gestis Antonj Caraphaei con el arquetipo biográfico de Plutarco y la prosa moral de Virgilio Malvezzi, presentando los resultados de estos estudios en la memorable convención celebrada en Sevilla en 1999, seguramente una de las más espléndidas y magníficas que se haya hecho sobre Vico.

Al igual que, mirando los antecedentes de Vico, B. trató de negar con estas investigaciones que este viviera "como si no hubiera libros en el mundo», así, en relación con todo lo escrito sobre su éxito en el siglo XVIII, intentó desmentir que la Scienza nuova, como escribió el propio autor en un momento de desaliento, fuese enviada «al desierto». Es aquí donde desarrolló las concordancias que unen a Vico con Alfonso de Liguori, por haber compartido el mismo aprendizaje jesuita, por la confianza común en la enseñanza de la retórica, por el papel decisivo de la religión y por el rechazo de los preadamitas. Y es aquí también donde mostró la fina aceptación que las ideas viquianas tuvieron en un lingüista del siglo XVIII, Idelfonso Valdastri, sin dejar de mencionar la influencia que las teorías homéricas y el constante devenir del lenguaje tuvieron sobre Melchiorre Cesarotti. De estos ensayos, aunque sea solo parcialmente, se extrae que Vico en su siglo no estuvo tan aislado como él mismo dijo de sí mismo y como Croce y Nicolini hicieron creer para proyectarlo sobre Hegel y sobre el idealismo, y más recientemente, en todos cuantos acogieron con complacencia esta iconografía del profeta no escuchado en su tiempo para poder realzarlo mejor en la actualidad. Sobre todo en Nápoles y en el Véneto tuvo lectores que lo valoraron tempranamente y que con el fin de probarlo acudieron a pruebas documentales. En verdad, no se puede decir que estas consideraciones hayan encontrado algún seguimiento entre los eruditos de Vico. El libro que las contiene, Vico tra antichi e moderni, de 2004, pasó desapercibido y ni siquiera llegó a vender 500 copias.

La escasa circulación de este libro fue de algún modo compensada por la relativa difusión que tuvo la colección comentada de las Opere de Vico, publicada en Meridiani Mondadori en 1990 y reeditada en 1999. Sin embargo cuenta más la experiencia que nace de estos extensos trabajos que su difusión, que en el mejor de los casos solo puede servir para satisfacer al narcisismo. El comentario sobre los textos viquianos, que duró continuamente desde 1982 hasta 1986, lo condujo a un crecimiento intelectual en múltiples direcciones. A nivel filológico, estudió concretamente la diacronía de las diversas ediciones de las "Scienze nuove" de 1725 y de 1744, cada una por separado, sin dejar de cotejar de forma sistemática las ediciones de Nicolini con alguna primera edición que permitió ver de cerca las bases del pensamiento viquiano. Naturalmente, este trabajo fue superado por las ediciones críticas editadas por Sanna y Cristofolini, pero, mientras tanto, la versión realizada por 
B. fue aceptada y reproducida en las sucesivas ediciones que publicaron ya fuera el Istituto Poligrafico, la Zecca dello Stato (2000) o la editorial Bompiani (2012). A nivel exegético, la obligación de comentar cada referencia bibliográfica, encontrando el punto exacto de cada palabra obsoleta, de cada referencia intra y extra textual, permitió conocer, por un lado, a autores y a repertorios eruditos que, de lo contrario, nunca hubieran sido estudiados y, por otro, hizo posible acercarse a la forma de trabajar de Vico y verificar la solidez real de sus lecturas. Después del arduo terreno de prueba que supuso la Scienza nuova, que trataba de todo, cada nuevo autor con el que tuvimos que enfrentarnos, aparte de Dante, nos pareció mucho más sencillo.

Precisamente debido a la riqueza incontenible de ideas, el pensamiento de Vico se presta a ser estudiado desde diferentes puntos de vista. Por esta razón, la experiencia de estudios anteriores demuestra que el enfoque más correcto es evitar propuestas unilaterales y exclusivas. La tendencia de los estudios filosóficos de este primer milenio y quizás también de los futuros, aun a costa de asumir riesgos en esta predicción, parece querer abandonar la perspectiva dicotómica de un Vico antirracionalista, impulsado por paradigmas y posturas anticientíficas. Incluso sus afirmaciones sobre el papel cognitivo del ingenio, la fantasía y la memoria ya no se colocan en contraposición con el papel de la razón, sino más bien en la búsqueda de un equilibrio entre todas las facultades involucradas en los procesos cognitivos. En consecuencia, ya no es un crítico irreductible de la razón, sino que investiga, más que la exclusión mutua, la mediación y la integración del componente racional con el componente ingenioso de la mente, estableciendo entre ambos un diálogo heurístico. Desde el momento en el que Vico ya no es entendido como un campeón del antirracionalismo, su relación con el pensamiento de Descartes también cambia, no en el sentido de que sus críticas al Discours de la méthode fallan, sino en el sentido de tener por objetivo la naturaleza «distinta» de las ideas, considerada inadecuada, porque al trazar los límites del acto de conocer negaba la realidad de un pensamiento humano cuya base era el equilibrio entre las distintas facultades involucradas en los procesos cognitivos.

Más que en la exclusión, parece más apropiado insistir en la integración mutua, incluso a nivel de las disciplinas del saber, en las que parece haberse abierto un nuevo frente -además de las relativas a la política, la sociología, el derecho, la pedagogía- incluso con la ciencia y la profesión médica, protagonista floreciente de la cultura napolitana. Estas enseñanzas sobre la fisiología humana han vuelto útiles a Vico, para quien la corporeidad de los orígenes se sitúa en la base del nacimiento del pensamiento, de acuerdo con una correlación de mente y cuerpo que todavía en los tiempos modernos establece conexiones entre el pensamiento y las emociones. Desde este punto de vista, se refuerza la idea de un Vico que, aunque alimentado por lecturas que entonces resultaban poco actuales, aún así era partícipe de los debates que florecieron entre sus coetáneos a principios del siglo XVIII en Nápoles. 
Es probable que sus raíces en el contexto cultural de su tiempo aún quedarán mejor demostradas en el futuro gracias al potencial de internet, que proporciona herramientas bibliográficas que hasta hace solo veinte años era imposible consultar. Ahora a B., en el ocaso de sus días, no le importaría poder concluir su diálogo con Vico dedicándole una biografía cultural que siente que falta, que fuese capaz de narrar, con una mirada panorámica y con suficiente detalle, su desarrollo intelectual y fundar en síntesis y orgánicamente las vicisitudes por las que pasó, considerándolo en sus circunstancias concretas y en su pensamiento, sin limitarlo a la filosofía, evitando tanto las soluciones reduccionistas como la yuxtaposición extrínseca entre vida y obra que es habitual en todas las monografias. Sin embargo, tal vez porque «en la edad temblorosa decae el estilo», como el mismo Vico escribió de sí mismo al llegar a la edad madura, puede ser que esta aspiración haya que colocarla entre los utópicos y vanos deseos de los que hablaba Bacon.

[Traducción del italiano por Amparo Zacarés Pamblanco]

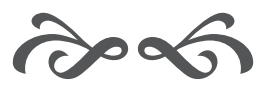

